\title{
Hearing loss in urban South African school children (grade 1 to 3 )
}

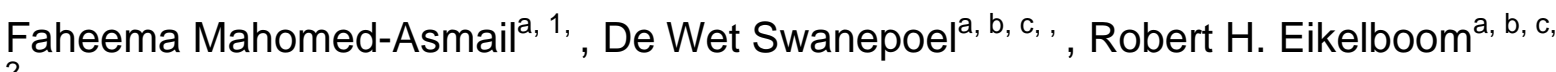
2,

aDepartment of Speech-Language Pathology and Audiology, University of Pretoria, Pretoria 0002, South Africa

${ }^{\mathrm{b}}$ Ear Science Institute Australia, Suite 1, Level 2, 1 Salvado Rd., Subiaco 6008, WA, Australia

${ }^{c}$ Ear Sciences Centre, School of Surgery, The University of Western Australia, Nedlands, WA, Australia

* Corresponding author at: Department of Speech-Language Pathology and Audiology, University of Pretoria, Room 3-5, Level 3, Corner Lynnwood and University Road, Pretoria, South Africa. Tel.: +27 12420 4280; fax: +27 124203517 .

E-mail addresses:

faheema.mahomed@up.ac.za (F. Mahomed-Asmail),

dewet.swanepoel@up.ac.za (D.W. Swanepoel),

rob.eikelboom@earscience.org.au (R.H. Eikelboom).

${ }^{1}$ Tel: +27 $124202490{ }^{2}$ Tel: +61 863804900 .

\section{Abstract \\ Objective}

This study aimed to describe the prevalence and characteristics of hearing loss in school-aged children in an urban South African population.

\section{Method}

Children from grade one to three from five schools in the Gauteng Province of South Africa formed a representative sample for this study. All children underwent otoscopic examinations, tympanometry and pure tone screening $(25 \mathrm{~dB} \mathrm{HL}$ at 1, 2 and $4 \mathrm{kHz}$ ). Children who failed the screening test and $5 \%$ of those who passed the screening test underwent diagnostic audiometry.

\section{Results}

A total of 1070 children were screened. Otoscopic examinations revealed that a total of $6.6 \%$ ears had cerumen and $7.5 \%$ of ears presented with a type-B tympanogram. 24 children (12 male, 12 female) were diagnosed with hearing loss. The overall prevalence of hearing loss was $2.2 \%$ with Caucasian children being 2.9 times more (95\% confidence interval, 1.2-6.9) likely to have a hearing loss than African children. 


\section{Conclusion}

Hearing loss prevalence in urban South African school-aged children suggest that many children (2.2\%) are in need of some form of follow-up services, most for medical intervention (1.2\%) with a smaller population requiring audiological intervention $(0.4 \%)$.

\section{Keywords}

School screening; Prevalence; Hearing loss; Developing countries; South Africa

\section{Abbreviations}

dB, Decibel; Hz, Hertz; NHS, newborn hearing screening; SNHL, sensorineural hearing loss; SD, standard deviation; SLM, sound level meter.

\section{Introduction}

The World Health Organization estimates that hearing loss is the most prevalent disabling condition globally [1]. In 2013 the global prevalence of disabling (>40 dB $\mathrm{HL}$ ) hearing loss was estimated at 360 million, with 32 million of these being children (<15 years) [1]. In developing areas of the world, where more than $80 \%$ of persons with hearing loss reside, there are limited prospects of early detection for hearing loss [1] due to a number of barriers. Numerous studies from developing areas of the world report varying hearing loss prevalence rates among school children. These figures range from 1.4\% in China [2] and 1.75\% in Saudi Arabia [3], to as high as $11.9 \%$ in India [4]. The varying ranges in prevalence is also seen in sub-Saharan Africa with prevalence ranging between $5.6 \%$ and $13.9 \%$ across studies in rural areas of Kenya [5] and Nigeria [6], respectively.

A number of studies have been conducted across South Africa to investigate the prevalence of middle ear pathology and sensorineural hearing loss (SNHL) in Caucasian and African children. Early studies indicated that the prevalence of middle ear pathology among young children varied between $13.4 \%$ and $29.4 \%$ [7], [8] and [9]. A study conducted on 2036 elementary school children (5-10 years of age) reported $5 \%$ of ears with indications of otitis media with effusion [10]. Similar findings were reported in a study of 2457 grade 1 children [11], with a prevalence of $6.5 \%$ of possible middle ear pathologies.

The prevalence of sensorineural hearing loss (SNHL) was reported to be $1.8 \%$ for children between the ages of 1 and 12 years [9], and $2 \%$ and $2.1 \%$ in two other communities [10] and [11]. Higher prevalence rates were reported in KwaZulu-Natal with $13 \%$ of black children and $14.3 \%$ for Indian children presenting with a sensorineural hearing loss [12]. The most recent study conducted in the Western Cape indicated a referral rate of $7.9 \%$ [13].

Although prevalence data have been previously reported [7], [8], [9], [10], [11], [12] and [13], the method of determining a hearing loss varied across the studies, with most basing it on screening outcome [9], [10] and [12] as opposed to a 
confirmed hearing loss with diagnostic audiometry. Furthermore, the screening protocol utilized in these studies varied in terms of the frequencies and screening levels employed for pass/refer criteria. For example, van Rooy [10] used a pass/refer criteria of $25 \mathrm{~dB} \mathrm{HL}$ or $30 \mathrm{~dB} \mathrm{HL}$, depending on the level of the background noise in the test environment. North-Matthiassen, Singh [13] and van Rooy [10] included $0.5 \mathrm{kHz}$ in the screening protocol, which resulted in an increased referral rate since $0.5 \mathrm{kHz}$ is more sensitive to noise and middle ear pathologies. In addition, many of these studies [7], [8], [9], [10] and [11] were conducted primarily on children from rural areas whose ages varied between preschool to school-going age.

The prevalence of hearing loss in children in developed countries is typically lower than in developing countries; $1.49 \%$ has been reported for the UK [14], $2 \%$ for Sweden [15], 2.5\% for Finland [16] and 3.6\% for Denmark [17]. Fortnum et al. [14] suggested that the reasons for differences in prevalence between developed and developing countries include the absence of regular hearing-screening programs, the impact of poverty and malnutrition, ignorance of hearing loss and paucity of accessible health care in developing countries.

School-based hearing screening in South Africa is required as part of the 2012 Integrated School Health Policy [18]. Unfortunately it is still far from common practice and screening is only available for a small minority of South African children [19]. In order to ensure availability of referral services careful evaluation and planning of school-based screening needs to be conducted [19]. Determining the prevalence of hearing loss in this population allows for adequate planning to ensure hearing health services are made available. Therefore, this study describes the prevalence and nature of hearing loss among school-aged children from grade one to three in a representative urban South African population.

\section{Materials and methods}

The investigation was conducted following approval from the Research Ethics Committee of the Faculty of Humanities, University of Pretoria and Gauteng Department of Education, South Africa.

\subsection{Study populations}

Five public government schools in underserved urban regions which served as a sample from the City of Tshwane, Gauteng Province, South Africa were utilized in this study. The schools were purposively selected from a list of government schools in the north western region of Tshwane. This area was selected as the population has a high unemployment rate, low incomes and poor living standards representative of the majority of South Africans [20]. All students in grade one to three within the school, who had signed consent from their parent/caregiver and who provided assent, were screened. A consecutive sample of 1070 school-aged children were screened which included Caucasian and African (Black, Coloured and Indian) individuals. 


\subsection{Data collection}

\subsubsection{Screening phase}

Screening was conducted by audiology students (40) from the University of Pretoria. As part of their practical training, under direct supervision of the first author who conducted validation checks throughout, they were required to complete five days of screening. Testing was conducted in a quiet room provided by the school. Sound in the test environment was measured with a sound level meter (RION, NA-24, Japan, Tokyo) prior to data collection and twice during the data collection session. Noise levels ranged between 42.5 and $79.6 \mathrm{dBA}$ (mean 65.1 SD 9.9).

Ears were examined using a handheld Welch Allyn [Welch Allyn, South Africa (Pty) Ltd.] or Heine mini 3000 (Heine, Germany) otoscope. Any abnormalities of the external ear canal and tympanic membrane were noted. Tympanometry was conducted to obtain information regarding the participant's middle ear status using one of two screening tympanometers: GSI Auto Tymp (Grayson Stadler, Eden Prairie, USA) or an Interacoustics Impedance Audiometer AT 235 (William Demant, Smørum, Denmark). Results were recorded in terms of middle ear pressure, static compliance and ear canal volume and classified based on the modified Jerger classification [21].

Each child was screened twice as part of a validation study [22], once with a conventional screening audiometer and once with a smartphone-based audiometer. For conventional screening the same screeners used for tympanometry were coupled with TDH 39P headphones (Telephonics, Huntington, N.Y.) to conduct the hearing screening. For smartphone screening, two sets of Samsung Galaxy Pocket Plus 55301 phones running the hearScreen ${ }^{\mathrm{TM}}$ Android OS application with supraaural Sennheiser HD202 II headphones (Sennheiser, Wedemark, Germany) were used. Screening audiometry was conducted, according to recommended guidelines [23] and [24] using a screening level of $25 \mathrm{~dB} \mathrm{HL}$ [22]. Immediately following a fail result, the child was rescreened using the same screening audiometer. All screeners were calibrated according to ISO 389-1 (1998) standards prior to data collection.

\subsubsection{Diagnostic phase}

Diagnostic audiometry was conducted on every child who failed one or both screenings (conventional and smartphone-based screen) and on $5 \%$ of the children who passed on both screenings [22], to determine the prevalence and nature of hearing loss. Diagnostic audiometry was performed with a KUDUwave (MoyoDotNet, Johannesburg, South Africa) Type 2 Clinical Audiometer (IEC $60645-1 / 2$ ). Testing was only conducted down to $15 \mathrm{~dB} \mathrm{HL}$ as hearing of children is considered normal if all thresholds are at or below $15 \mathrm{~dB} \mathrm{HL}$ [25] and [26]. Diagnostic air- and bone-conduction was determined across 0.5, 1, 2, $4 \mathrm{kHz}$. Airconduction pure tones were delivered via deeply inserted insert foam tips covered by circumaural earcups with forehead placement bone-conduction audiometry conducted with both ears occluded by the deep insertion of the insert earphones. Testing was conducted in a natural environment provided by the school, which constituted either a classroom, administrative or media room. Thresholds were recorded using the routine $10 \mathrm{~dB}$ descending and $5 \mathrm{~dB}$ ascending method (modified Hughson-Westlake method) 
commencing at $1000 \mathrm{~Hz}$ at $40 \mathrm{~dB} \mathrm{HL}$ in the left ear. A continuous contralateral effective masking level of $20 \mathrm{~dB} \mathrm{HL}$ above the air-conduction threshold of the non-test ear was used for the forehead bone-conduction audiometry [24].

The KUDUwave software actively monitored ambient noise levels across octave bands throughout both test procedures. Whenever the noise exceeded the maximum ambient noise level allowed for establishing a threshold, the audiologist waited for the transient noise to subside.

\subsection{Data analysis}

Diagnostic audiometry results confirming a hearing loss provided the prevalence rate for this sample population. A hearing loss was defined as having at least one threshold more than $15 \mathrm{~dB} \mathrm{HL}$ at $0.5,1,2$ and $4 \mathrm{kHz}$ in either ear [25] and [26]. The AMCLASS $^{\circledR}$ classification criteria was used to classify audiograms [27]. A hearing loss was classified as conductive when a $10 \mathrm{~dB}$ air-bone gap at three or more frequencies, or a $15 \mathrm{~dB}$ air-bone gap at any one frequency was present, whereas a sensorineural hearing loss was noted when the configuration was not normal ( $\leq 15 \mathrm{~dB} \mathrm{HL}$ ) and there was no significant air-bone gap. A unilateral hearing loss was obtained when one ear had normal hearing and the other had a hearing loss, with a bilateral hearing loss indicative of a hearing loss was present in both ears. The participants were allocated into age groups: $<7$ years of age, from 7 to $<9$ years of age, and 9 years of age and greater.

Data analysis was done using SPSS v22 (Chicago, Illinois). Demographic data, otological status, tympanometric findings and screening results were analysed and presented using descriptive statistics. A binary logistic regression was performed to evaluate the effect of age, gender and race on the presence of a hearing loss in the sample, with the significant level at $p<0.01$.

\section{Results}

A total of 1070 consecutively screened children were included in the study with a mean age of 8 years ( $\pm 1.1 \mathrm{SD}$; Range 6 to 12 years). Demographic distribution (Table 1) was $50.7 \%$ female and $83.5 \%$ African (16.5\% Caucasian). The mean age of the African group (7.9 years, $1.0 \mathrm{SD}$ ) was significantly lower ( $t$-test, $p<0.01$ ) than the Caucasian group (8.3 years, 1.1 SD). The most commonly spoken languages were Sotho (39.7\%), Afrikaans (16.3\%), English (15.9\%), Zulu (8.8\%) with $19.3 \%$ speaking one of the other official languages of South Africa.

Only one child who referred both screens was excluded from the data analysis as the child could not be conditioned for diagnostic audiometry. A total of 125 children (61 failed on one or both screens, 64 passed on both screens) were tested diagnostically with 24 children diagnosed with a hearing loss indicating a hearing loss prevalence of $2.2 \%$ (12 male, 12 female). The youngest age group had a higher prevalence of hearing loss when compared to the older groups $(6.2 \%$ versus $1.7 \%$ and $1.3 \%$, respectively) (Table 1 ). However, binary logistic regression revealed no significant age and gender effect. Race had a significant effect $(p>0.01)$ indicating caucasian children to be 2.9 times [95\% Confidence Interval $(\mathrm{Cl}), 1.2-6.9]$ more likely to have a hearing loss than African children. 
Table 1. Demographic findings across study population and across children with hearing loss $(\mathrm{HL})$.

\begin{tabular}{|c||l|l||}
\hline Characteristics & $\%$ Of total $(\boldsymbol{n})$ & $\%$ Children with HL (n) \\
\hline \hline Gender & & \\
\hline \hline Male & $49.3 \%(528)$ & $2.3 \%(12)$ \\
\hline \hline Female & $50.7 \%(542)$ & $2.2 \%(12)$ \\
\hline \hline Race & & \\
\hline \hline African & $83.5 \%(893)$ & $1.7 \%(15)$ \\
\hline \hline Caucasian & $16.5 \%(177)$ & $5.1 \%(9)$ \\
\hline \hline Age & & \\
\hline \hline$<7$ years & $16.3 \%(175)$ & $6.2 \%(11)$ \\
\hline 7 to $<9$ years & $33.8 \%(362)$ & $1.7 \%(6)$ \\
\hline \hline$\geq 9$ years & $49.8 \%(533)$ & $1.3 \%(7)$ \\
\hline
\end{tabular}

Conductive hearing loss (57.1\%) was the most common type of hearing loss that presented both unilaterally (29.2\%) and bilaterally (25.0\%) (Table 2). Of the 20 ears that presented with a conductive hearing loss, 13 had normal middle ear functioning, five ears presented with type B tympanograms, one ear presented with a type $\mathrm{C} 2$ tympanogram and only one with a perforated eardrum (Table 4). Furthermore, five children presented with a pure sensorineural hearing loss of varying degrees (1 mild, 2 mild-to-moderate, 2 severe to profound) (Table 3 ).

Table 2. Nature of hearing loss present across subjects $(n=24)$.

\begin{tabular}{|c|c|}
\hline \multicolumn{1}{|c|}{ Types } & $\%(\boldsymbol{n})$ \\
\hline \hline Bilateral conductive & $25.0 \%(6)$ \\
\hline \hline Bilateral sensorineural & $8.3 \%(2)$ \\
\hline \hline Bilateral mixed & $8.3 \%(2)$ \\
\hline \hline Unilateral conductive & $29.2 \%(7)$ \\
\hline Unilateral sensorineural & $12.5 \%(3)$ \\
\hline \hline Unilateral mixed & $16.7 \%(4)$ \\
\hline
\end{tabular}


Table 3. Characteristics of hearing loss across ears $(n=35)$.

\begin{tabular}{||c|c|}
\hline Characteristics & $\%(\boldsymbol{n})$ \\
\hline Type of hearing loss & \\
\hline \hline Conductive & $57.1 \%(20)$ \\
\hline \hline Sensorineural & $20.0 \%(7)$ \\
\hline \hline Mixed & $22.9 \%(8)$ \\
\hline \hline Laterality & \\
\hline \hline Unilateral & $37.1 \%(13)$ \\
\hline Bilateral & $31.4 \%(11)$ \\
\hline Degree of deafness & \\
\hline \hline Mild & $48.6 \%(17)$ \\
\hline \hline Mild-to-moderate & $17.1 \%(6)$ \\
\hline Moderate-to-Severe & $14.3 \%(5)$ \\
\hline \hline Severe-to-Profound & $20.0 \%(7)$ \\
\hline
\end{tabular}

Table 4. Modified Jerger (1989) classification of middle ear (ME) findings $(n=1070)$.

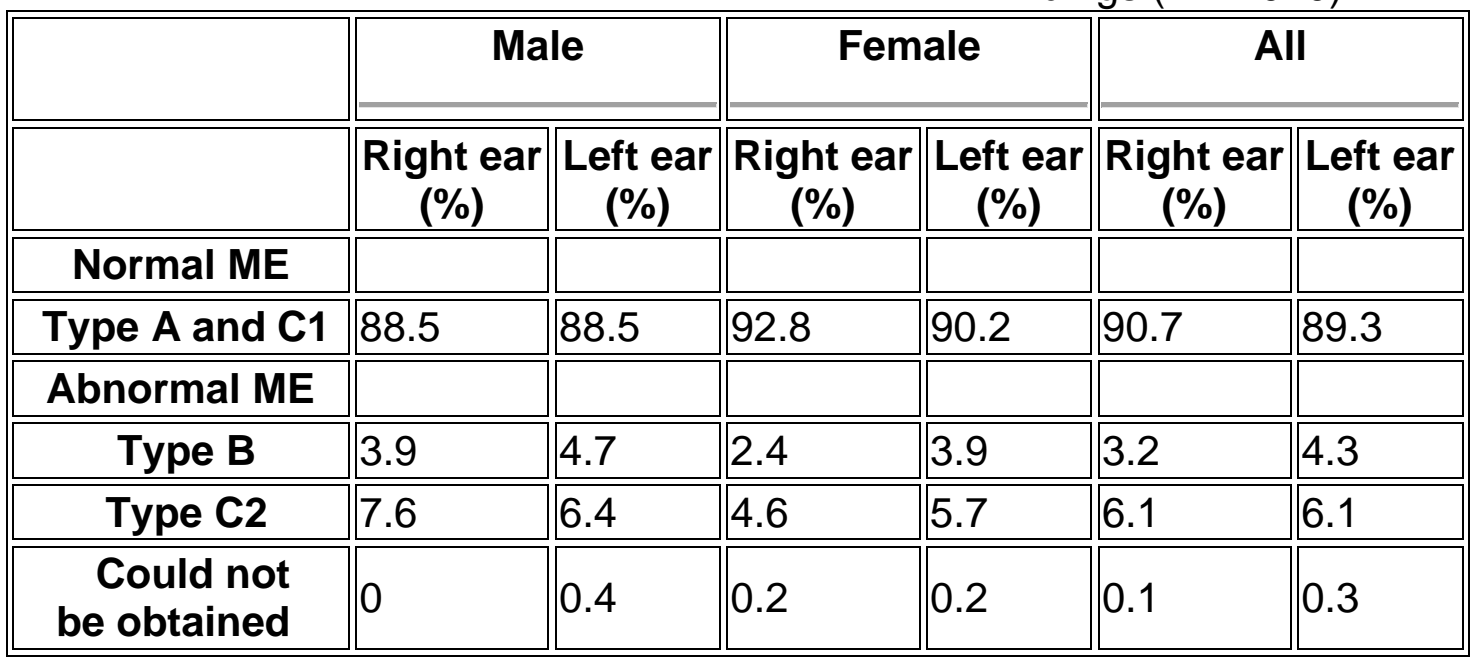

Type A-admittance $\geq 0.2 \mathrm{ml} \&$ ME pressure between -99 and +200 da Pa; Type C1-admittance $\geq 0.2 \mathrm{ml} \& \mathrm{ME}$ pressure between -199 and $-100 \mathrm{da} \mathrm{Pa}$; Type B-admittance $\leq 0.2 \mathrm{ml}$ or ME pressure $\leq-400$, Type C2-admittance $\leq 0.2 \mathrm{ml} \& \mathrm{ME}$ pressure $\leq-400 \mathrm{da} \mathrm{Pa}$.

The most common otoscopic examination finding across the entire sample, excluding a normal ear canal and tympanic membrane $(92.1 \%)$, was the presence of $>75 \%$ cerumen in the ear canal $(6.6 \%)$.

\section{Discussion}

This study revealed a hearing loss prevalence of $2.2 \%$. This is similar to prevalence findings from longitudinal studies conducted in developed countries, such as the $1.8 \%$ in USA [28], 2\% in Sweden [15] and 2.5\% in Finland [16]. These studies were conducted to determine the prevalence of hearing loss in preschool children over 4 
to 10 year period utilizing a pass criteria of $20 \mathrm{~dB} \mathrm{HL}$ as opposed to $25 \mathrm{~dB} \mathrm{HL}$ used in this study. A higher prevalence rate would therefore be expected in the current study sample compared to those from developed countries if the same intensity level of $20 \mathrm{~dB} \mathrm{HL}$ was used. Furthermore, the prevalence obtained in this study are far less than the 7.9\% [13] and the 5.6\% [5] reported among previous African studies. A possible reason for the higher rate reported in these studies may be due to the fact that prevalence reported in these studies were based on referral rates and not on audiological diagnostic test findings. Based purely on referral rates, the current study had a prevalence of 5.6\% similar to those previously reported [10], [11] and [13].

Middle ear effusion is more common in younger children [3] and [29] and may explain the higher prevalence rate of hearing loss in the youngest population of this study (4.9\%). One in three conductive hearing losses presented with type B tympanogram and minimal wax. Furthermore, the second most common otoscopic finding was $>75 \%$ cerumen in the ear canal (6.6\%), however, only $0.7 \%(8 / 1070)$ of these participants failed the screening. On further investigation seven of the participants presented with normal hearing and only one had a mild conductive component at $1 \mathrm{kHz}$. Excessive or impacted ceruman has been reported by other studies to be one of the most frequent and common ear disorders [5].

No gender effects were noted in this study (Table 1), in accordance to those previously reported [5], [13] and [30]. However, there was a significant effect $(p>0.01)$ of race with Caucasian children 2.9 times more likely to have a hearing loss than African children. The higher prevalence of hearing loss for children in the Caucasian group (5.1\%) is in agreement with earlier studies from South Africa [10]. The reason attributed to this phenomenon in an earlier study was due to a higher prevalence of otitis media with effusion and retracted tympanic membranes in the Caucasian group compared to the African group [10]. Furthermore, a study in adults [31] indicated that Caucasians were also more likely to have hearing loss followed by non-Caucasian, black individuals.

Unilateral hearing losses $(54.2 \%, 13 / 24)$ were more common than bilateral losses, in line with results reported by North-Matthiassen and Singh [13]. A bilateral hearing loss may affect many areas of a child's development such as their language, social, psychosocial and behavioural development [32]. However, children who present with unilateral hearing losses also have an increased rate of grade failure, need additional educational assistance and have perceived behavioural issues, which could deteriorate their educational achievement and ultimately vocational outcomes [32]. As a result hearing loss identification, whether unilateral or bilateral, requires effective management in school-aged children to minimize these adverse effects.

This study provides prevalence data of hearing loss in a representative urban South African sample which assists in effective resource planning for the provision of school-based hearing health care services. A follow-up study is recommended to determine the follow-up services and referral pathways available in resource-limited countries like South Africa. 


\section{Conclusion}

Hearing loss prevalence in school-aged children suggest that many children (2.2\%) are in need of some form of follow-up service, most for medical intervention and a smaller number for audiological intervention. These findings provide valuable baseline data for realistic planning and appropriate implementation of hearing health services to ensure hearing screening is employed sustainably across South Africa for all children in accordance with the Integrated School Health Policy.

\section{Conflict of interest statement}

The authors have no conflict of interest to disclose.

\section{Acknowledgements}

The authors would like to acknowledge the audiology students who assisted with the hearing testing and the children and schools who participated in this study. Furthermore, financial assistance of the National Research Foundation (NRF) towards this research is hereby acknowledged. Opinions expressed, and conclusions arrived at, are those of the authors and are not necessarily to be attributed to the NRF.

\section{References}

[1] World Health Organization. Millions of People in the World have a Hearing Loss that Can be Treated or Prevented. World Heal. Organ. (2013) 〈http://0www.who.int.innopac.up.ac.za/pbd/deafness/>

[2] J. Lü , Z. Huang, T. Yang, Y. Li, L. Mei, M. Xiang, et al., Screening for delayedonset hearing loss in preschool children who previously passed the newborn hearing screening, Int. J. Pediatr. Otorhinolaryngol. 75 (2011) 1045-1049, http://dx.doi.org/ 10.1016/j.jporl.2011.05.022.

[3] M.A. Al-Rowaily, A.I. AlFayez, M.S. AlJomiey, A.M. AlBadr, M.A. Abolfotouh, Hearing impairments among Saudi preschool children, Int. J. Pediatr. Otorhinolaryngol. 76 (2012) 1674-1677, http://dx.doi.org/10.1016/j.jporl.2012.08.004.

[4] R.S.P. Rao, M.A. Subramanyam, N.S. Nair, B. Rajashekhar, Hearing impairment and ear diseases among children of school entry age in rural South India, Int. J. Pediatr. Otorhinolaryngol. 64 (2002) 105-110, http:// dx.doi.org/10.1016/S0165- 5876(02)00032-0.

[5] J. Hatcher, A. Smith, I. Mackenzie, S. Thompson, I. Bal, I. Macharia, et al., A prevalence study of ear problems in school children in Kiambu district, Kenya, Int. J. Pediatr. Otorhinolaryngol. 33 (1995) 197-205, http://dx.doi.org/10.1016/ 01655876(95)012095. 
[6] B.O. Olusanya, A.A. Okolo, G.T.A. ljaduola, The hearing profile of Nigerian school children, Int. J. Pediatr. Otorhinolaryngol. 55 (2000) 173-179.

[7] C. Celliers, D. Rossouw, S. Meyer, M. Hurter, Die aard en voorkoms van middeloorpatologieë in laerskole vir normaalhorende blanke kinders, S. Afr. J. Commun. Disord. 35 (1988) 35-37.

[8] S. Meyer, C. Van den Berg, Die voorkomsfrekwensie van oor- en gehoorpatologie by kinders in die afgesonderde gemeenskap van TsikundaMalema, S. Afr. J. Commun. Disord. 32 (1985) 71-75.

[9] J. Meyer, M. Hurter, F. Van Rensburg, Gehoorsiftingsresultate van 'n groep kleurlingkinders, S. Afr. J. Commun. Disord. 34 (1987) 43-47.

[10] C.H. van Rooy, J.G. Swart, J. Op't Hof, A.C. Vlantis, M.R.I. Ahmed, P.H.<ET.AL> Venter, Diagnosis and treatment of ear disease among children in the Ellisras district: an outreach programme, S. Afr. Med. J. 85 (1995) 675-677.

[11] S. Swart, Prevalence of hearing loss and ear disease in first year entry school children in the industrial areas of Witbank/Kwa Guqa, South Africa, CHASA J. Compr. Health 7 (1996) 95-100.

[12] D. Bhoola, S.R. Hugo, Prevalence: outer and middle ear disorders in Black and Indian preschool children from Durban, S. Afr. J. Commun. Disord. 42 (1995) 19-27.

[13] C. North-Matthiassen, S.A. Singh, The hearing profile among learners in schools in the Western Cape, South Africa, Int. J. Pediatr. Otorhinolaryngol. 71 (2007) 113118, http://dx.doi.org/10.1016/j.ijporl.2006.09.012.

[14] H.M. Fortnum, Q. Summerfield, D.H. Marshall, A.C. Davis, Prevalence of permanent childhood hearing impairment in the United Kingdom and implications for universal neonatal screening: questionnaire based ascertainment study, BMJ 323 (2001) 1-6.

[15] N. Darin, P. Hanner, K. Thiringer, Changes in prevalence, aetiology, age at detec tion, Dev. Med. Child Neurol. 39 (1997) 797-802.

[16] I. Marttila, Results of audiometrical screening in Finnish school children, Int. J. Pediatr. Otorhinolaryngol. 11 (1986) 39-46.

[17] A. Parving, Hearing screening aspects of epidemiology and identification of hearing impaired children, Int. J. Pediatr. Otorhinolaryngol. 49 (1999) 287-292.

[18] Integrated School Health Policy, Department of Basic Education and Department of Health, Integrated School Health Policy, Pretoria: South Africa, 2012.

[19] M. Shung-King, From "Stepchild of primary healthcare" to priority programme: lessons for the implementation of the National Integrated School Health Policy in South Africa, S. Afr. Med. J. 103 (2013) 895-898, http://dx.doi.org/10.7196/SAMJ.7550. 
[20] A. Ganief, J. Thorpe, City of Tshwane General and Regional Overview, 2013 Retrieved from:

http://www.parliament.gov.za/content/Tshwane_General_and_Regions_Report_201 3.pdf.

[21] G.A. Zielhuis, E.W. Heuvelmans-Heinen, G.H. Rach, P. van den Broek, Environmental risk factors for otitis media with effusion in preschool children, Scand. J. Prim. Health Care 7 (1989) 33-38.

[22] F. Mahomed-Asmail, D.W. Swanepoel, R. Eikelboom, H.C. Myburgh, J. Hall III, Clinical validity of hearScreenTM smartphone hearing screening for school children, Ear Hear. 37 (2016) 11-17.

[23] American Academy of Audiology, Clinical Practice Guidelines Childhood Hearing Screening, American Academy of Audiology, 2011.

[24] American Speech-Language-Hearing Association, Guidelines for Audiologic Screening, American Speech-Language-Hearing Association, Rockville, MD, 1997, http://dx.doi.org/10.1044/policy.GL1997-00199.

[25] R.J.H. Smith, J.F. Bale, K.R. White, Sensorineural hearing loss in children, Lancet 365 (2005) 879-890, http://dx.doi.org/10.1016/S0140-6736(05) 710473.

[26] J.G. Clark, Uses and abuses of hearing loss classification, ASHA 23 (1981) 493-500.

[27] R.H. Margolis, G.L. Saly, C. Le, J. Laurence, Qualind: a method for assessing the accuracy of automated tests, J. Acad. Audiol. 18 (2007) 78-89.

[28] A.C. Serpanos, Quantitative and qualitative follow-up outcomes from a preschool audiologic screening program: perspective over a decade, Am. J. Audiol. 16 (2007) 4-12.

[29] D.W. Swanepoel, R.H. Eikelboom, R.H. Margolis, Tympanometry screening criteria in children ages 5-7 yr, J. Am. Acad. Audiol. 25 (2014) 927-936, http://dx.doi.org/ 10.3766/jaaa.25.10.2.

[30] A. Jacob, A. Rupa, V. Job, N. Joseph, Hearing impairment and otitis media in a rural primary school in South India, Int. J. Pediatr. Otorhinolaryngol. 39 (1997) 133138.

[31] E. Helzner, J. Cauley, S. Pratt, S. Wisniewski, J. Zmuda, E.O.A. Newman, et al., Race and sex differences in age-related hearing loss: the health, aging and body composition study, J. Am. Geriatr. Soc. 53 (2005) 2119-2127, http://dx.doi.org/ 10.1111/j.1532-5415.2005.5.x0052.

[32] S.M. Swart, R. Lemmer, J.N. Parbhoo, C.A.J. Prescott, A survey of ear and hearing disorders amongst a representative sample of Grade 1 school children in Swaziland, Int. J. Pediatr. Otorhinolaryngol. 95 (1995) 23-34. 